\title{
Full of eggs and no place to lay them: hidden cost of benthic development
}

\author{
Yasmin J. von Dassow ${ }^{1}$, Richard R. Strathmann ${ }^{2, *}$ \\ ${ }^{1}$ Dept. of Earth Sciences, University of California, Riverside, California 92521, USA \\ ${ }^{2}$ Friday Harbor Laboratories and Department of Zoology, University of Washington, 620 University Road, Friday Harbor, \\ Washington 98250, USA
}

\begin{abstract}
The scarcity of sites suitable for attaching eggs may be a hidden cost to depositing embryos in benthic aggregations. We tested this hypothesis with the bubble-shell snail Haminaea vesicula, which lives on mud or sand but requires firm substrata for attaching its eggs. In pools on a sandflat where firm substrata were scarce, the preferred substrata were but a small fraction of the total available firm substrata. Abundant drifting green algal blades comprised 1 to $11 \%$ cover but were rarely used for egg deposition. Substrata commonly used for egg deposition totaled less than $1 \%$ cover, and included attached and drifting eelgrass, drifting branched red algae, bivalve shells, and attached green algal blades. In choice experiments, the snails preferred to deposit eggs on branched red algae and eelgrass, with bivalve shells next and green algal blades last. To test the hypothesis that substratum availability limits egg deposition, we added artificial eelgrass made of duct tape to tidepools inhabited by the snails. The mean number of egg ribbons laid $\mathrm{m}^{-2}$ in the experimental areas was 20 to 360 times that in control areas, and the mean number of adult snails present and egg ribbons per adult snail were greater in the experimental areas. Also, more egg ribbons per adult were deposited on artificial eelgrass when it was positioned away from natural eelgrass patches, indicating that distances of a few meters affect availability of substrata for deposition. The results imply that in this habitat the snails travel to scarce substrata for egg deposition, with whatever costs in time, energy, or risk that may be associated with travel. Scarcity of suitable sites for benthic egg masses can limit an apparently safe mode of development. Habitats that regularly support adult populations can differ greatly in suitability for egg deposition, but this limitation may not be apparent without experimental intervention.
\end{abstract}

KEY WORDS: Benthic $\cdot$ Deposition site $\cdot$ Development $\cdot$ Egg deposition $\cdot$ Egg mass $\cdot$ Substratum selection Resale or republication not permitted without written consent of the publisher

\section{INTRODUCTION}

Habitat and modes of development affect risk in reproduction and early development. Some benthic marine animals are free spawners, and their embryos develop in the plankton. Other animals attach their embryos to the bottom in masses protected by gelatinous coats or capsule walls. Estimated mortality rates indicate greater safety for embryos on the sea floor than for pelagic embryos or larvae (Strathmann 1985, Rumrill 1990, Ohman and Hirche 2001, López-Urrutia et al. 2004). If embryos in protected aggregations on the seabed are safer than those singly adrift in the plankton (Pechenik 1979), why do so many animals commit their embryos to pelagic development?

Broadcasting gametes or zygotes is an ancestral trait in many clades; nevertheless, protection of aggregated embryos has evolved many times (Pechenik 1999), and some lineages have reverted to a pelagic development (Strathmann 1974, McEdward 1992, Rouse \& Fitzhugh 1994). Thus, although there may be ancestral constraints on benthic protection, there is sufficient flexi- 
bility in evolution of developmental mode to warrant examination of costs and benefits of benthic versus pelagic embryonic development.

Some of the processes involved have been considered at length. These include parental investment in protective coats, mortality rates, and dispersal of pelagic embryos and larvae. Yet scarcity of suitable sites for egg deposition as a potentially important cost of benthic development has received little attention (Spight 1977). Benthic embryonic mortality rates, as studied thus far, may be low because egg masses are deposited at sites selected for safety by the mother. Examples are a snail's egg capsules near anemones that protect them from sea urchins (Shimek 1981), a fish's spawn and a sea slug's egg ribbons in sites shaded from solar radiation (Marliave 1981, Biermann et al. 1992), or a fish's eggs at sites guarded by males (DeMartini 1991, Hastings 1992, Warner et al. 1995). Safe places to lay eggs can be scarce, especially for animals that live on mud or sand but require firm substrata for deposition of large numbers of eggs (Pechenik 1978, Brenchley 1981). Site scarcity may result in costs from long distances and travel times for the purpose of egg deposition or in deferral of reproduction in the absence of substrata.

Habitats that support large adult populations may not be suitable for benthic egg masses, and a scarcity of sites for egg deposition may not be evident without experimental intervention. We examined scarcity of deposition sites for the bubble-shell snail Haminaea

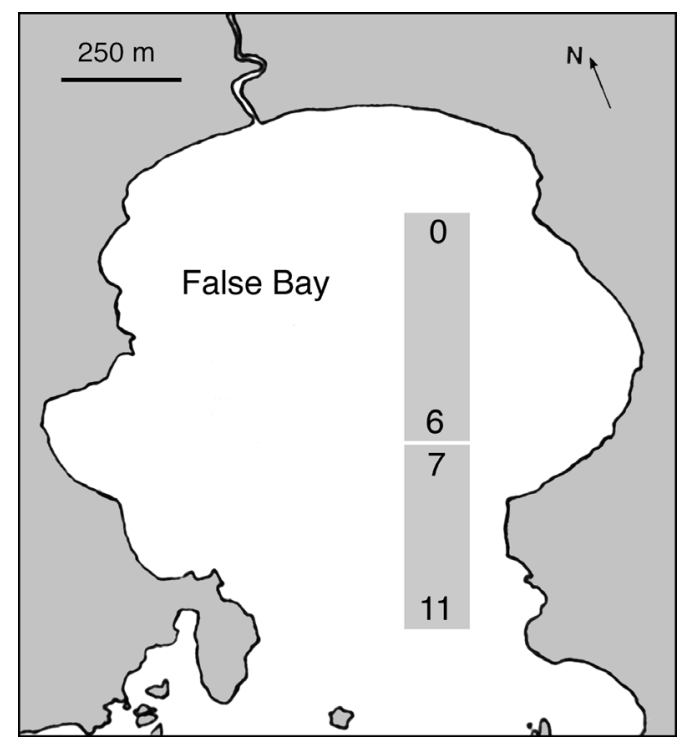

Fig. 1. The study sites in pools in False Bay, San Juan Island, USA, were within the area designated by shaded rectangles. The shaded rectangle at the inner end of the bay includes sites in Pools 0 to 6, where substrata for egg deposition were scarce. The shaded rectangle near the bay mouth includes sites in Pool 7 to Pool 11, with patches of rooted eelgrass vesicula (a cephalaspidean gastropod) in False Bay (an intertidal sandflat on San Juan Island, Washington state, northeast Pacific). Like many opisthobranchs, $H$. vesicula is an annual species with a few months of reproduction before death (Gibson \& Chia 1991). These snails can grow to reproductive size on sand or mud substrata but do not deposit egg ribbons directly on soft sediments (Gibson \& Chia 1989, 1991). After several days of development, offspring hatch as pelagic larvae, which feed, grow, and presumably disperse for several weeks before becoming competent to settle (Gibson \& Chia 1989).

False Bay is nearly circular and about $1 \mathrm{~km}$ in diameter (Fig. 1). Low tide exposes an extensive intertidal sandflat with long interconnected pools and low emergent sand ridges (Fig. 2). Rooted eelgrass Zostera marina is very scarce in the pools at the inner end of the bay but is more abundant seaward, toward the bay mouth, where pools are nearly covered with eelgrass (Ruckelshaus 1998). Adults of Haminaea vesicula (Fig. 3) occur in the pools or the wet edges of pools but rarely on the bars that emerge at low tide. They deposit egg ribbons within the pools, not on the bars. Where eelgrass and adults co-occur, adults crawl on the plants and attach large numbers of egg ribbons to the grass blades. Where eelgrass is absent, the adults lay on available substrata, such as drifting plants or bivalve shells (Fig. 3). In preliminary experiments, addition of firm substrata to pools without eelgrass increased the number of egg ribbons deposited per area (C. S. Cohen, C. A. Kelly, S. G. Morgan, J. A. Schmidt unpubl.). This increase implied that suitable deposition sites were scarce. We have now demonstrated scarcity of sites by documenting (1) the adults' preferences for substrata in choice experiments, (2) the natural abundance and use of firm substrata for egg deposition and (3) the effect of addition of substrata on numbers of egg ribbons deposited.

\section{MATERIALS AND METHODS}

Site and habitat. The study area (Figs. 1 \& 2) crossed 12 pools and intervening exposed bars. The position and shape of the pools changed little during $3 \mathrm{yr}$ of observation. Pools were numbered from 0 at the inner end to 11 near the mouth of the bay (Fig. 1). Eelgrass was scarce from Pool $0\left(48^{\circ} 29.26^{\prime} \mathrm{N}, 123^{\circ} 3.94^{\prime} \mathrm{W}\right)$ to Pool $6\left(48^{\circ} 29.07^{\prime} \mathrm{N}, 123^{\circ} 4.03^{\prime} \mathrm{W}\right)$. Patches of eelgrass greater than $1 \mathrm{~m}$ in length occurred from Pool 7 $\left(48^{\circ} 29.02^{\prime} \mathrm{N}, 123^{\circ} 4.06^{\prime} \mathrm{W}\right)$ to the mouth of the bay at Pool $11\left(48^{\circ} 28.87^{\prime} \mathrm{N}, 123^{\circ} 4.14^{\prime} \mathrm{W}\right)$. The most extensive patches of eelgrass were at the bay mouth, in Pool 11. During the reproductive season in 2002, most adults and egg ribbons were in the inner bay where rooted 
eelgrass was very scarce. By late summer, abundance of adults and egg ribbons had increased in the more seaward pools (especially Pool 7), but this was not the habitat for most reproduction. Reproduction has shifted seaward earlier in some other years. Our experiments were during peak reproduction (June through mid-August) in the inner pools. Most observations were made in 2002. Those made in 2001 and 2003 are noted below. Our observations were within $1.5 \mathrm{~h}$ of lower low water during spring tides, when most pools were about $20 \mathrm{~m}$ wide. At low tide, depths of Pools 0 to 6 were 10 to $20 \mathrm{~cm}$.

Preference for substrata. We tested for substratum preference by offering the snails replicated clusters of

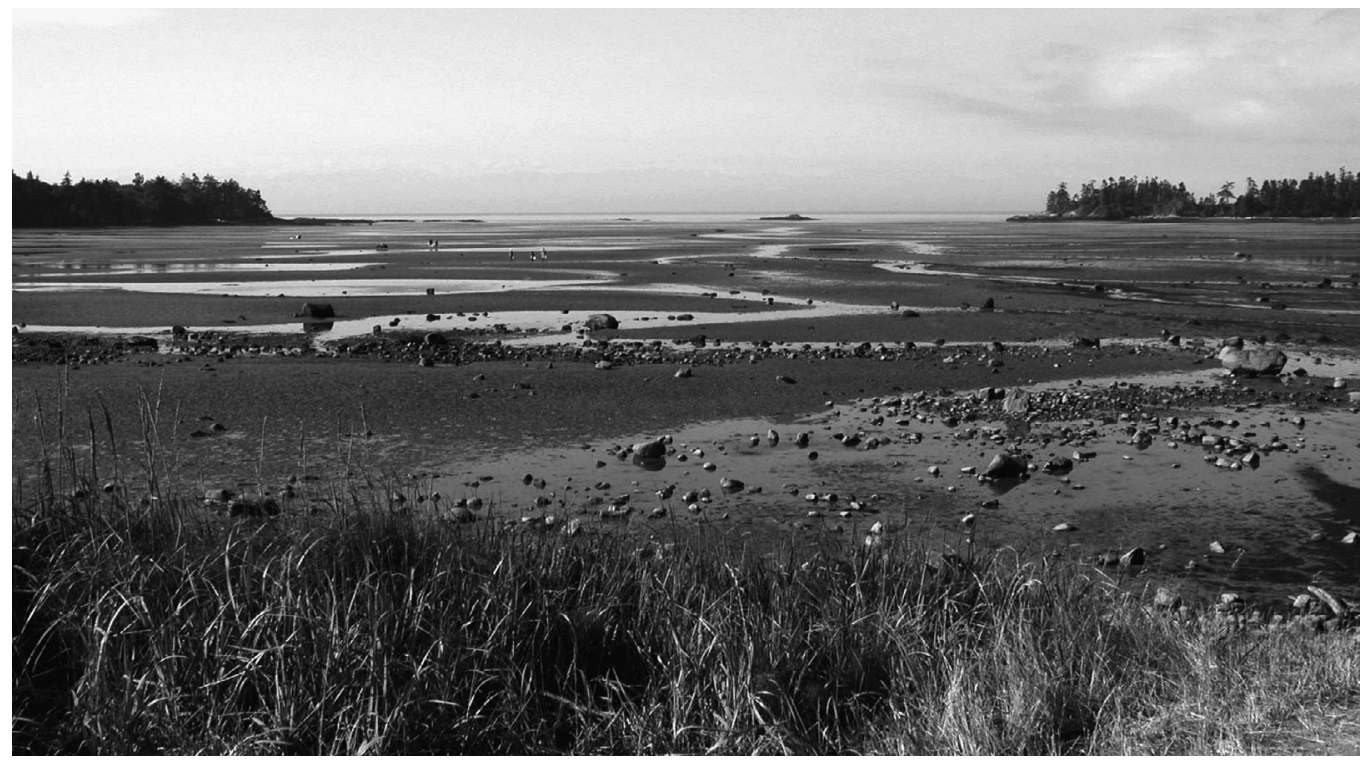

Fig. 2. Pools and exposed ridges on the sand flat of False Bay at low tide. Pool 0 is beyond the line of scattered rocks. Pool 11 is near the distant line of trees and the point of bedrock to the left, near the bay mouth. Adults and egg deposition of Haminaea vesicula are in pools, not on ridges

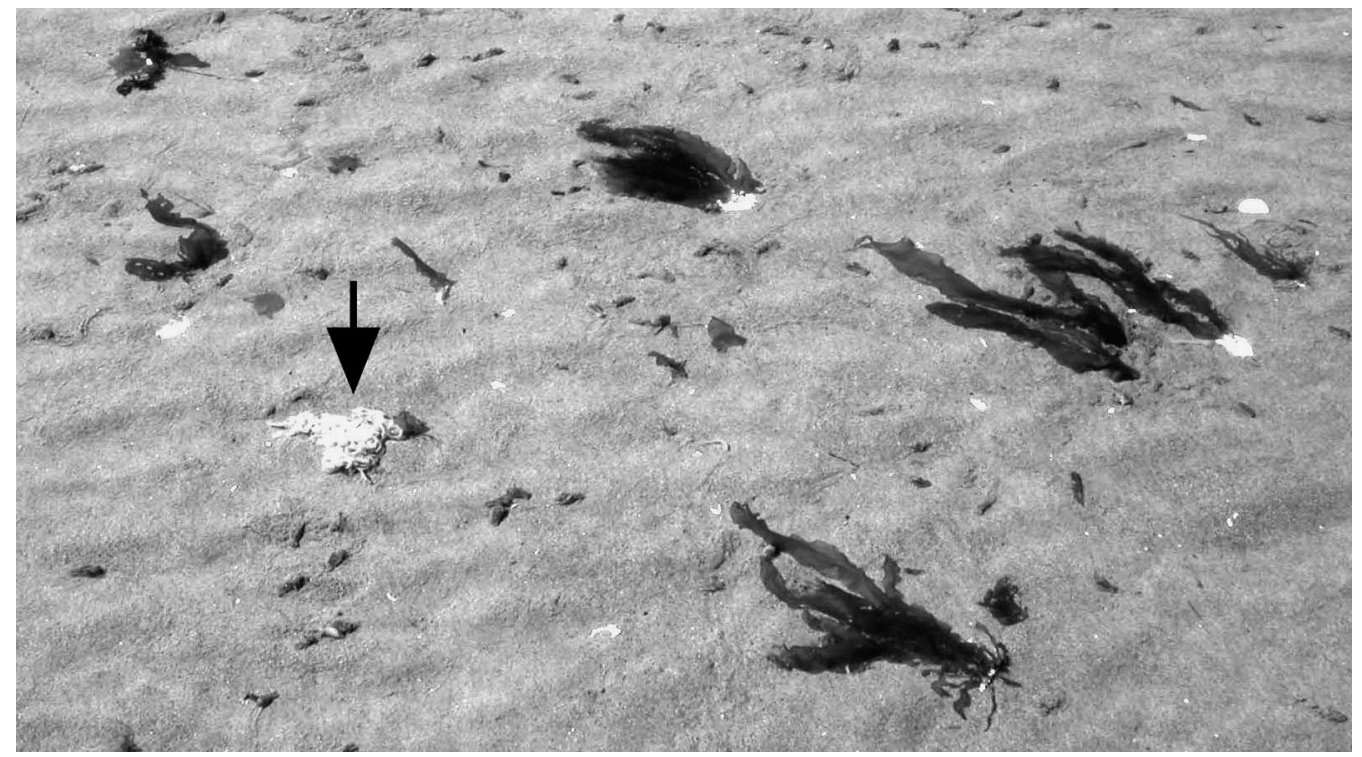

Fig. 3. Haminaea vesicula. Adults and egg ribbons of the cephalaspidean gastropod immersed within a pool in False Bay at low tide. The small oblong dark spots are adults; body lengths are about $3 \mathrm{~cm}$. The white spots are shells of bivalves, Macoma spp. Egg ribbons of $H$. vesicula (arrow) are attached to one of these shells. Green algae Ulva linza are attached to other shells 


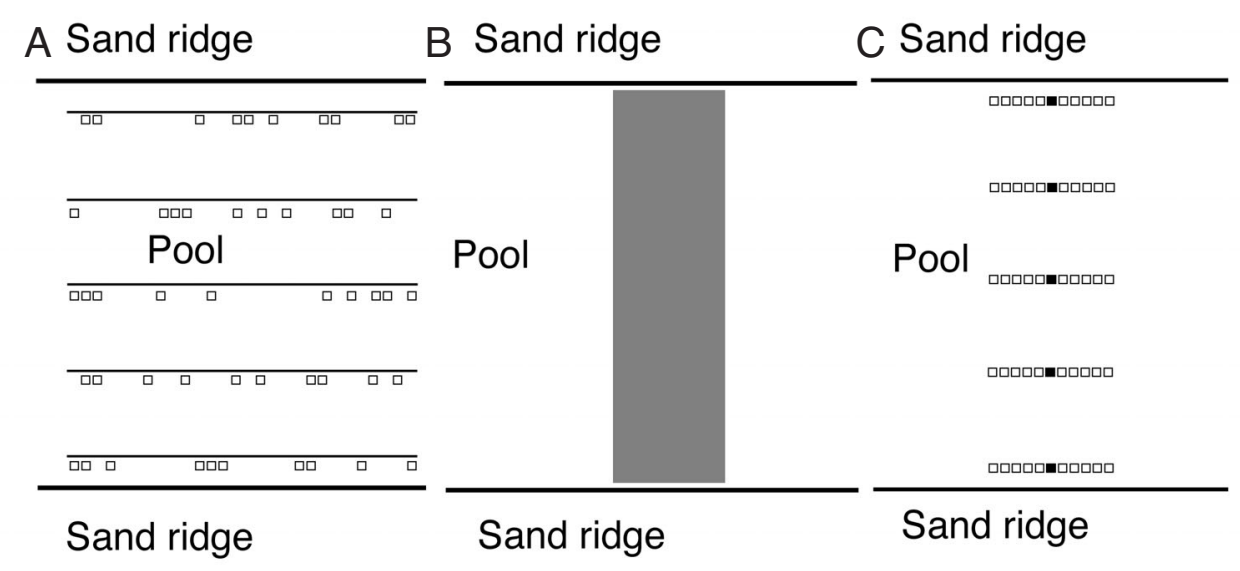

Fig. 4. Haminaea vesicula. Placement of quadrats for sampling and experiments. (A) Example of quadrats randomly positioned along transect lines for estimates of percent cover of substrata. (B) Entire rectangular area across a pool for estimates of density of egg ribbons on each kind of substratum. (C) Quadrats with experimental addition of artificial eelgrass (filled squares) and control quadrats (open squares) in Pools 0 and 4. (Trial 1, in June had only 1 control quadrat on each side of each experimental quadrat.) Experimental quadrats had 4 artificial eelgrass shoots, each shoot with 8 blades. Each quadrat was $0.16 \mathrm{~m}^{2}$

substrata. We used plastic-coated wire ties ('twist-ties') to tether different substrata to holes in the ends of PVC pipe (21 mm outer diameter, $63 \mathrm{~cm}$ long) pounded into the sand. This arrangement avoided cages and the accumulation of drifting plants that would provide alternative substrata for egg deposition. Tethered substrata were deployed in Pool 5, where other firm substrata were scarce and no other experiments had been conducted. The tethered substrata in 2 multiple choice trials were green algal blades (sheet-like thalli) of Ulva linza attached to fragments of shells of Macoma spp., bare shells of Macoma spp. (with both valves wide open and joined by the ligament, placed convex side upward), eelgrass shoots (Zostera marina), and branched red algae found as drift (Ceramium washingtoniense). We used attached $U$. linza because studies of background abundance showed that more egg ribbons were deposited on it than on other ulvaceans, and because drifting ulvaceans could not be tethered without damage. A third trial compared deposition on the 2 substrata most commonly used in False Bay: shells of Macoma spp. and blades of Z. marina. Areas were measured for 1 side of each substratum. Estimates of areas of eelgrass blades were calculated from their lengths and widths. Area for densely filamentous red algae was area within a line connecting the branch tips. Areas ranged from 8 to $72 \mathrm{~cm}^{2}$ for eelgrass blades (the smallest substratum) to 16 to $96 \mathrm{~cm}^{2}$ for $U$. linza (the largest substratum). We compared numbers of ribbons per substratum and also numbers per estimated area of substratum.

Abundance of substrata and egg ribbons. Firm substrata were not equally scarce in the pools, and we needed to demonstrate that the substrata used for egg deposition were indeed scarce. Differences in abun- dance of substrata, adults, and egg ribbons necessitated different sampling methods. In each sampled pool, we estimated background abundance of adults and percent cover of substrata with $40 \times 40 \mathrm{~cm}$ $\left(0.16 \mathrm{~m}^{2}\right)$ quadrats positioned randomly along 5 or 6 transects, $10 \mathrm{~m}$ in length and with 10 quadrats per transect (Fig. 4A). Random numbers were from Rohlf \& Sokal (1969). The transect lines ran parallel to the edges of the long pools and were deployed at equal intervals from one edge of a pool to the other, with each transect at an approximately constant depth. We estimated percent cover of substrata by the method of Dethier et al. (1993), with areas of substrata estimated as in the test for preferences. Adults and egg ribbons were counted in each quadrat. Because the adults can burrow into the sand, we raked each quadrat with our fingers in order to find and include all adults. At this season all the sampled snails in this annual species were in a narrow size range and counted as adults.

Accurate estimates of egg ribbon densities on each kind of substratum required counts of egg ribbons in larger areas. Within rectangular areas extending from one edge of a pool to the other (Fig. 4B), we counted all egg ribbons and recorded the substratum of each. This method sampled areas ranging from 80 to $400 \mathrm{~m}^{2}$ of pool, with area dependent on time available.

Size of egg ribbons. We tested whether snails experiencing scarcity of deposition sites compensated by depositing larger egg masses. In 2003 we measured egg ribbons collected from patches of rooted eelgrass where firm substrata (eelgrass) were abundant (Pool 7) and from old drift eelgrass blades where firm substrata were scarce (Pool 6). We also compared ribbons deposited in the laboratory by adults collected from these 2 pools and habitats to see if adults previously 
without abundant deposition sites deposited egg masses of a different size. Each adult was isolated in a mesh-sided container placed in running seawater. Each day during $5 \mathrm{~d}$, the first ribbon deposited by an adult was measured for length and width of the ribbon and spacing of the rows of embryos in the ribbon.

Addition of artificial eelgrass. To test if scarcity of substrata limits deposition of egg ribbons, we supplemented some pools with artificial eelgrass. Adult Haminaea vesicula were known to attach egg ribbons to duct tape in the field (R. Podolsky pers. comm.). We therefore made artificial eelgrass by attaching strips of duct tape (33 cm long) at the end of PVC pipe (21 mm outer diameter, $63 \mathrm{~cm}$ long), with the tape in 2 layers joined by the adhesive sides, so that no adhesive was exposed. To add buoyancy and prevent burial of the strips, we sandwiched a $35 \mathrm{~mm}$ wide strip of $3 \mathrm{~mm}$ thick foam packing material between the tape layers about $25 \mathrm{~mm}$ from the free end. The tape was then cut longitudinally into 8 strips, each $6 \mathrm{~mm}$ wide, a common width for blades of Zostera marina in False Bay. When the PVC pipe was pounded into the sand, the strips extended above the sand as a single shoot of artificial eelgrass with 8 diverging blades, each blade about 25 to $30 \mathrm{~cm}$ long. Other kinds of artificial seagrass have been used in field experiments (e.g. Keough 1986), with the advantages over transplanted eelgrass of durability, constant area, and conservation of existing natural eelgrass.

We added artificial eelgrass to pools with numerous adult snails and scarce firm substrata (Pools 0 and 4). Patches of 4 artificial shoots were placed in a $40 \times$ $40 \mathrm{~cm}\left(0.16 \mathrm{~m}^{2}\right)$ quadrat with each shoot within a different $20 \times 20 \mathrm{~cm}$ square. Five of these experimental quadrats (artificial eelgrass patches) were spaced at 4 $\mathrm{m}$ intervals across the width of the pool, from edge to edge (Fig. 4C). In the first trial, control quadrats (each $40 \mathrm{~cm}$ by $40 \mathrm{~cm}$ ) were in 2 parallel lines across the width of the pool, spaced $1.5 \mathrm{~m}$ to either side of each of the artificial eelgrass quadrats. In the next 3 trials (to increase sampling of controls, where ribbons were scarce) 5 adjacent control quadrats were positioned in a line to either side of each quadrat with an artificial eelgrass patch (Fig. 4C).

We estimated production of egg ribbons per adult snail by sampling egg ribbons and adults in experimental and control quadrats after 6 to $8 \mathrm{~d}$ in Pool 4 and after 7 to $11 \mathrm{~d}$ in Pool 0. The intervals allowed accumulation of egg ribbons for about the duration of benthic development, which allowed comparison of abundances of egg ribbons accumulated on the artificial eelgrass to abundances on natural substrata. Times from day of deposition to hatching are 12.2, 7.3, and $4.8 \mathrm{~d}$ at 10,14 , and $18^{\circ} \mathrm{C}$, respectively (J. M. Staver \& R. R. Strathmann unpubl.). The temperatures in the pools commonly change from about 10 to $>20^{\circ} \mathrm{C}$ during summer tidal cycles (Podolsky 2003) as cold water entering from Haro Strait on each flood tide is warmed within the bay.

Effect of presence of natural eelgrass patches on deposition on artificial eelgrass. We expected that snails would deposit more ribbons on an artificial substratum where suitable substrata were scarce than they would where substrata were abundant. Therefore, we compared egg deposition on artificial eelgrass shoots that were near and distant from eelgrass patches. In a 2 wk experiment in July 2001, artificial eelgrass was deployed near and far from rooted eelgrass at widely separated sites within False Bay. Three landward pools with scarce substrata were contrasted with eelgrass patches in 3 seaward pools, with 2 of the landward and 2 of the seaward pools to the west of the study area in Fig. 1. There were 2 duct-tape blades per shoot, 3 to 5 shoots per pool, with shoots separated by more than $1 \mathrm{~m}$ within pools. We counted egg ribbons on artificial eelgrass shoots and adults in $0.64 \mathrm{~m}^{2}$ quadrats centered on each artificial shoot.

In late June and early July of 2002 we tested effects of short distances from natural substrata by deploying rows of 5 artificial eelgrass shoots (with 8 blades per shoot) near 2 small eelgrass patches within Pool 2. The artificial eelgrass shoots were placed within each small patch of natural eelgrass and also at distances of $3 \mathrm{~m}$ to one side of a patch and $6 \mathrm{~m}$ to the other, along the axis of the pool. Only 1 artificial eelgrass row was placed on each side of a natural eelgrass patch because more than 1 row would have confounded effects of distance from real and artificial eelgrass. The individual artificial eelgrass shoots were in a line, $20 \mathrm{~cm}$ apart from one another. Adult snails (including those below the sand surface) were sampled in non-overlapping $20 \times$ $40 \mathrm{~cm}$ quadrats that were centered on artificial eelgrass shoots. Egg ribbons on the duct-tape eelgrass blades and adults from the associated quadrats were counted and egg ribbons removed on 25 June after $15 \mathrm{~d}$ for the group at patch 1 and $12 \mathrm{~d}$ for the group at patch 2 . The next trials were terminated on 7 July after $12 \mathrm{~d}$ for both groups.

\section{RESULTS}

\section{Preference for substrata}

In 4-way choice experiments, snails in 2 trials deposited more eggs on branched red algae (Ceramium washingtoniense) and eelgrass (Zostera marina) than on shells of Macoma spp., and more on the shells than on blades of the green alga Ulva linza (Table 1). In each trial, deposition on the different substrata dif- 
Table 1. Haminaea vesicula. Choice of substrata for deposition of egg ribbons in the field, with types of substrata presented in groups of 4 or 2 choices and 5 replicate groups in each $3 \mathrm{~d}$ trial. Lines for significant differences are at $\mathrm{p}<0.05$ by a Tukey-type non-parametric multiple comparison (Trials 1 and 2) and by a Wilcoxon signed ranks test (Trial 3)

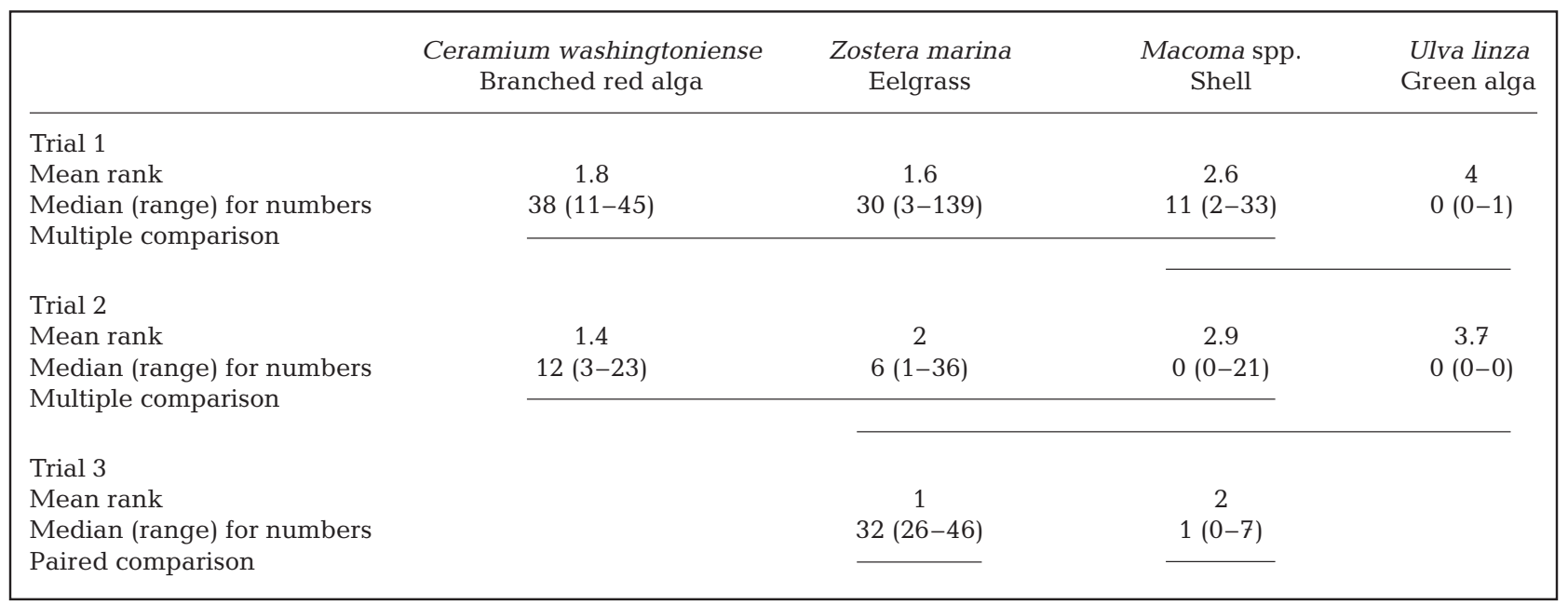

fered significantly (Kruskal-Wallis test on ranked numbers of egg ribbons in each group offered, $\mathrm{p}<0.005$, $\mathrm{n}=5$ groups of substrata). The overall ranking of deposition was eelgrass and filamentous red algae $>$ shell $>$ green algal blades. The ranking was consistent in the 2 trials, but there was high variation in deposition on the substrata. A Tukey-type non-parametric multiple comparison (Zar 1984) demonstrated significant differences between deposition on eelgrass and blades of $U$. linza but not between eelgrass and shell or between shell and blades of $U$. linza (Table 1). Dividing each ribbon count by area of the substratum resulted in only 1 reversal of ranks in 1 tethered group and no change in results of statistical tests.

To further resolve preferences, another trial at the same site compared deposition on blades of eelgrass and the shells of Macoma spp. Deposition on the 2 substrata differed significantly (Wilcoxon signed ranks test, $\mathrm{p}<0.05, \mathrm{n}=5$ paired comparisons), with more deposition on the eelgrass than on the shells (Table 1). Dividing each ribbon count by area of the substratum made no change in results of the statistical test.

\section{Abundance of substrata and egg ribbons}

Substrata for egg deposition were scarce in the pools inhabited by adult Haminaea vesicula. Data from repeated samples in Pools 0 and 4 are in Fig. 5. Samples on 11 June in Pool 2 and on 13 June in Pool 6 were similar to those in Fig. 5 in that percent cover was greatest for drifting blades of green algae of the genera Ulva and Ulvaria; in the 6 samples from 4 pools, abundance of these algae ranged from 0.9 to $11.3 \%$, but this kind of substratum had only a small proportion of the egg ribbons.

Percent cover of substrata commonly used for egg deposition totaled less than $1 \%$ in all pools sampled, with attached green algal blades (Ulva linza) $<0.3 \%$, bivalve shells (mostly Macoma spp.) <0.25\%, attached and drifting eelgrass (Zostera marina) $<0.2 \%$, and drifting branched red algae (commonly Ceramium washingtoniense) $<0.2 \%$. Other substrata included drifting pieces of trees and the brown alga Fucus gardneri and were consistently scarce. None of the few rocks present in the bay occurred in sampled areas, and there were no ribbons on rocks in the bay. Drifting egg ribbons without substrata were a small proportion of the total egg ribbons sampled (Fig. 5); they were a higher proportion of the total in pools at the inner end of the bay where ribbons were scarcer overall, as in Pool 0 (Fig. 5). Thus the most common type of substratum (drifting green algal blades) had few egg ribbons. Scarce substrata (eelgrass and bivalve shells) had most of the egg ribbons.

\section{Size of egg ribbons}

Mean lengths and widths of egg ribbons deposited where eelgrass was abundant were similar to lengths and widths of ribbons deposited where substrata were scarce ( $t$-tests, p > 0.30). Egg ribbons were $47.2 \pm$ $13.4 \mathrm{~mm}$ long by $6.0 \pm 0.9 \mathrm{~mm}$ wide in the eelgrass patch and $50.8 \pm 11.5 \mathrm{~mm}$ long by $6.0 \pm 0.9 \mathrm{~mm}$ on the old eelgrass drift blades (mean $\pm \mathrm{SD}, \mathrm{n}=12$ )

Similarly, in the laboratory adults deposited egg ribbons of similar length, width, and spacing of rows of 

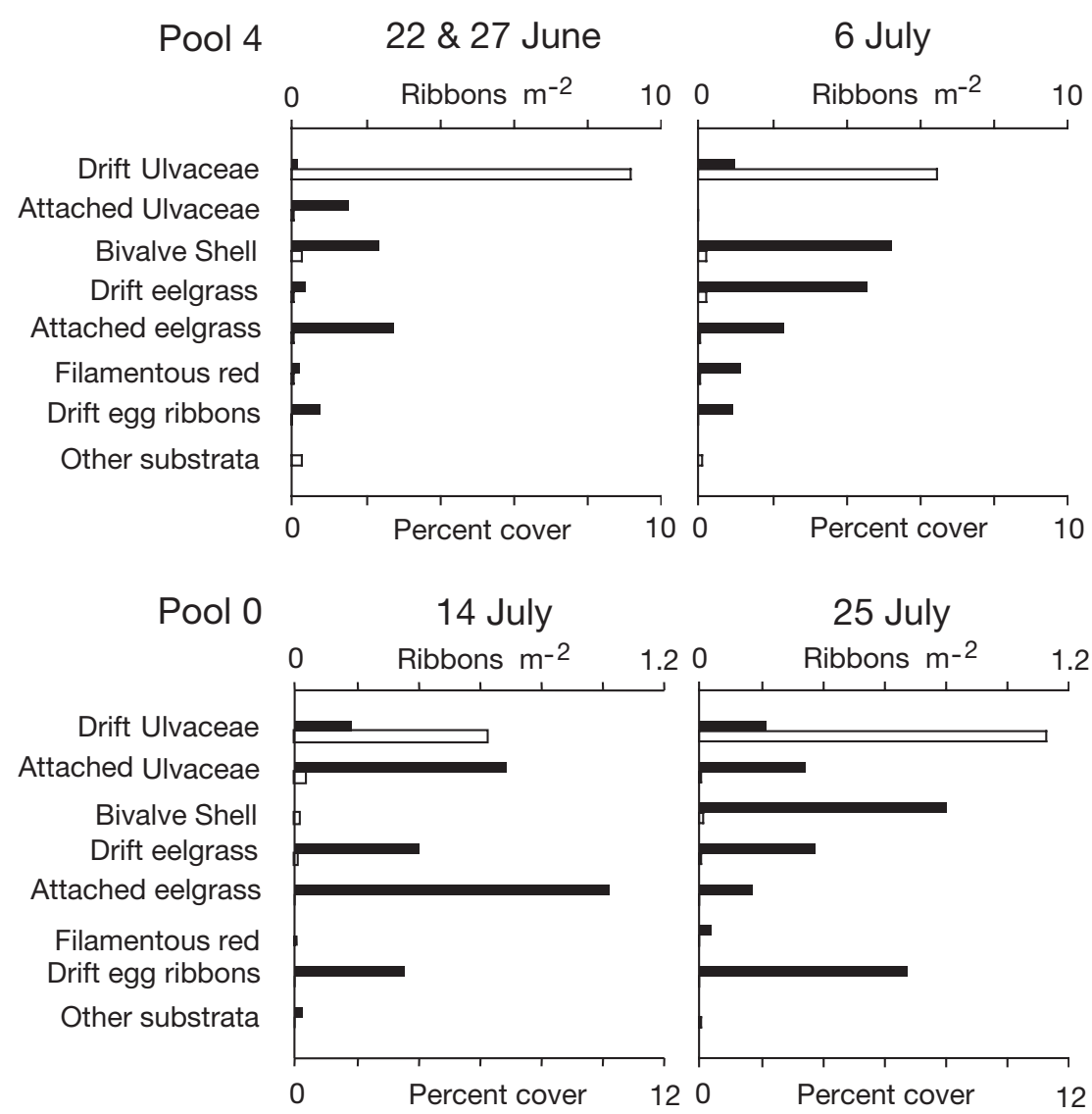

Fig. 5. Haminaea vesicula. Egg ribbons per area of pool that were associated with different substrata (black bars) and percent cover of substrata (white bars). Top panels: samples in Pool 4 with dates. (Data from samples on 2 different days in June were combined.) Bottom panels: samples in Pool 0 with dates

embryos whether the adults were collected from a natural eelgrass patch (with no limitation on deposition sites) or from sand in pools without rooted eelgrass (with scarce deposition sites) (Table 2). There were no significant differences in the measures of egg ribbons or in adult shell lengths ( $t$-tests, $\mathrm{p}>0.30)$. There was also no significant difference in a measure that combined ribbon size and density of embryo rows: (length $\times$ width) $/$ (row spacing). There was no evidence that scarcity of deposition sites was associated with differences in the size of egg ribbons. Counts of egg rib-

Table 2. Haminaea vesicula. Comparison of sizes of egg ribbons deposited in the laboratory by adults collected from an eelgrass patch in Pool 7 and from sand without eelgrass in Pool 6. Measurements are in $\mathrm{mm}$. Data are mean \pm $\mathrm{SD}(\mathrm{n})$ with no significant differences ( $t$-tests, $\mathrm{p}>0.30$ for all comparisons)

\begin{tabular}{|lcccc|}
\hline & \multicolumn{2}{c|}{ Adults from eelgrass } & \multicolumn{2}{c|}{ Adults from sand } \\
\hline Ribbon length & $42.6 \pm 9.3$ & $(8)$ & $43.2 \pm 15.1$ & $(12)$ \\
Ribbon width & $5.7 \pm 0.7$ & $(8)$ & $5.6 \pm 0.5$ & $(12)$ \\
Spacing of embryo rows & $0.226 \pm 0.031$ & $(8)$ & $0.242 \pm 0.045$ & $(12)$ \\
Adult shell length & $12.9 \pm(0.9)$ & $(8)$ & $13.2 \pm 0.9$ & $(11)$ \\
& & & & \\
\hline
\end{tabular}

bons, which were used in all other sampling and experiments, appeared to be an adequate measure of egg deposition for comparisons.

\section{Effect on egg deposition of addition of artificial eelgrass}

Egg deposition increased with addition of artificial eelgrass in all 4 trials (Table 3, Fig. 6). The quadrats with duct-tape artificial eelgrass received significantly greater density of egg ribbons in each trial (Wilcoxon signed ranks tests, onetailed, $\mathrm{p}<0.05, \mathrm{n}=5$ paired comparisons in each trial). All of the egg ribbons in the experimental quadrats were deposited on the duct-tape blades or on exposed tops of the PVC pipe bearing the blades, with the lowest densities of egg deposition near the edges of the pools (Fig. 6). Densities in the experimental quadrats were 21,53 , 64, and 362 times those in the control quadrats. 
Table 3. Haminaea vesicula. Effect of addition of duct-tape artificial eelgrass on density of egg ribbons and adults in 4 trials. Mean (SE) for densities of egg ribbons and adults and ratio of totals for egg ribbons per adult for experimental and control treatments. For each estimate for egg ribbons and adults, $n=5$

\begin{tabular}{|c|c|c|c|c|c|c|c|c|}
\hline \multirow[t]{2}{*}{ Pool } & \multirow{2}{*}{$\begin{array}{l}\text { Duration } \\
\text { (d) }\end{array}$} & \multirow{2}{*}{$\begin{array}{l}\text { End } \\
\text { date }\end{array}$} & \multicolumn{2}{|c|}{ Egg ribbons $\mathrm{m}^{-2}$} & \multicolumn{2}{|c|}{ Adults $\mathrm{m}^{-2}$} & \multicolumn{2}{|c|}{ Egg ribbons adult ${ }^{-1}$} \\
\hline & & & Duct-tape & Control & Duct-tape & Control & Duct-tape & Control \\
\hline 4 & 6 & $28 \mathrm{Jun}$ & $365(220)$ & $6.9(3.9)$ & $86(20)$ & $5.6(2.9)$ & 4.2 & 1.2 \\
\hline 4 & 8 & $6 \mathrm{Jul}$ & $640(182)$ & $30.4(11.8)$ & $178(52)$ & $11.2(3.0)$ & 3.6 & 2.7 \\
\hline 0 & 7 & $14 \mathrm{Jul}$ & $289(207)$ & $4.5(2.6)$ & $158(57)$ & $7.6(2.0)$ & 1.8 & 0.6 \\
\hline 0 & 11 & $25 \mathrm{Jul}$ & $1122(715)$ & $3.1(2.7)$ & $288(114)$ & $11.0(7.6)$ & 3.9 & 0.3 \\
\hline
\end{tabular}

Adults accumulated at the quadrats with artificial eelgrass patches (Table 3). Densities of adults were greater in the experimental than in the control quadrats (Wilcoxon signed ranks tests, 1-tailed, p < 0.05, $\mathrm{n}=5$ paired comparisons in each trial).

There were also more ribbons per adult in the experimental quadrats (Table 3). The greater numbers of egg ribbons per adult in experimental quadrats was significant (and samples for each statistical test independent) when results were separately grouped for the first trial in each pool and then for the second trial in each pool (Wilcoxon signed ranks tests, 2-tailed, $\mathrm{p}<$ $0.05, \mathrm{n}=8$ for trial $1, \mathrm{n}=9$ for trial 2). Combining data from 2 different pools avoided a repeated measure on the same group of snails within a pool. We could not demonstrate significant differences in ribbons per adult for experimental and control quadrats within single trials (one pool and date) because sample sizes for testing differences in egg ribbons per adult were small. This was especially true for the 2 trials for which we could not include quadrats with no adults. However, in each of the trials, the mean and median for ribbons per adult was greater in the quadrats with artificial eelgrass. Thus, overall, ribbons per adult increased with the addition of artificial eelgrass. These results indicate that the adults did not just shelter in the artificial eelgrass. Adults that concentrated at the artificial eelgrass also deposited large numbers of egg ribbons on it.

The experimental quadrats accumulated adult snails, but there was no indication of a decrease in deposition in the nearby control quadrats. Densities of egg ribbons in control quadrats (Table 3) were similar to background densities of egg ribbons near the beginning and end of the trials (sampled by transect lines or large sections of the pools, Fig. 4A,B). These background densities were 8.8, 8.2, and 13.7 ribbons $\mathrm{m}^{-2}$ in Pool 4 on 22 and 27 June and 6 July; 2.5 and 2.6 ribbons $\mathrm{m}^{-2}$ in Pool 0 on 14 and 15 July. Also, densities of adults in control quadrats (Table 3) were similar to densities estimated from transect samples: $15.8,8.6$, and 7.6 adults $\mathrm{m}^{-2}$ in Pools 2, 4, and 6 in June. Comparisons of the experimental and control quadrats were therefore an adequate estimate of the effect of an increase in substrata suitable for egg deposition.

Fig. 6. Haminaea vesicula. Effect of addition of artificial (duct-tape) eelgrass patches on density of egg ribbons and adults. Top panels: trials in Pool 4 with termination dates. Bottom panels: trials in Pool 0 with termination dates. O: Ribbon density in quadrats with artifical eelgrass; $\mathrm{X}$ : density in control quadrats. Values for controls are means of 2 quadrats for Pool 4 on June 28 and for 10 quadrats for all other dates and pools. Distance is from the landward toward the seaward edge of a pool on a low spring tide 
The ratio of egg ribbon densities in experimental and control quadrats indicates the area of natural habitat necessary to contain the same number of egg ribbons as were deposited on artificial eelgrass. In these 4 trials, addition of substratum to $0.8 \mathrm{~m}^{2}$ of a pool resulted in egg deposition equivalent to that in 17 to $290 \mathrm{~m}^{2}$ of natural habitat in the pools, as estimated from the control quadrats. Numbers of adults in experimental quadrats of $0.8 \mathrm{~m}^{2}$ were equivalent to those in 12 to $21 \mathrm{~m}^{2}$ of pools.

\section{Effect of presence of natural eelgrass patches on deposition on artificial eelgrass}

Two experiments contrasted deposition of egg ribbons on artificial eelgrass where substrata were scarce (no rooted eelgrass) and abundant (in eelgrass patches). Our prediction was that if adults are experiencing scarce deposition sites, they will deposit more egg ribbons on a standard substratum when it becomes available. In 2001, the number of ribbons deposited per adult in landward pools with scarce substrata was more than 10 times greater than the mean number of ribbons per adult for seaward pools in eelgrass patches. When quadrat data were pooled for each habitat, the difference in egg ribbons per adult was significant at $\mathrm{p}=0.02$ (Mann-Whitney $U$-test, $\mathrm{n}=9$ for landward and 9 for seaward pools, cases with no adults excluded). Deposition on artificial eelgrass per nearby adult was greater in the inner part of the bay, where natural sites for egg deposition were scarcer. The distances between inner pools without rooted eelgrass and seaward pools with rooted eelgrass is on the order of hundreds of meters (Fig. 1).

In 2002, we examined deposition on artificial eelgrass over shorter distances from natural eelgrass patches within Pool 2. In this pool, deposition sites were scarce except for 2 small patches of rooted eelgrass. An effect of distance was apparent for egg ribbons on artificial eelgrass per nearby adult (Table 4) and significant at $\mathrm{p}<0.05$ (2-factor ANOVA with fixed factors, $n=29$ in each trial, quadrats without any adults omitted). Effects of differences between the 2 eelgrass patches and the interaction of patch and distance were not significant. In both trials, the numbers of egg ribbons per adult at $6 \mathrm{~m}$ from the eelgrass patch were significantly different from those within the eelgrass patch (Tukey HSD test, $\mathrm{p}<0.05$ ). The mean number of egg ribbons on artificial eelgrass per nearby adult consistently increased with distance from the natural eelgrass (Table 4), but deposition at $6 \mathrm{~m}$ was significantly different from deposition at $3 \mathrm{~m}$ in only 1 of the 2 trials, and differences between 3 and $0 \mathrm{~m}$ were not significantly different in either trial. The results of the exper-
Table 4. Haminaea vesicula. Mean (SE) for egg ribbons on artificial (duct-tape) eelgrass and adults in $0.4 \times 0.2 \mathrm{~m}$ quadrats at 3 distances from eelgrass patches ( $\mathrm{n}=5$ at each distance) and ratio of egg ribbons per adult ( $\mathrm{n}=4$ or 5 ; no ratio for quadrats without any adults). Dates are for end of each trial

\begin{tabular}{|c|c|c|c|c|}
\hline & $\begin{array}{l}\text { Egg } \\
\text { ribbons }\end{array}$ & $\begin{array}{l}\text { Adults } \\
0.08 \mathrm{~m}^{-2}\end{array}$ & $\begin{array}{l}\text { Egg ribbons } \\
\text { adult }^{-1}\end{array}$ & $\mathrm{n}$ \\
\hline \multicolumn{5}{|c|}{25 Jun, patch 1} \\
\hline $0 \mathrm{~m}$ & $4.0(2.3)$ & 20.8 (5.6) & $0.24(0.13)$ & 5 \\
\hline $3 \mathrm{~m}$ & $6.0(2.0)$ & 19.8 & $0.31(0.10)$ & 5 \\
\hline $6 \mathrm{~m}$ & $6.6(1.7)$ & $10.8(1.6)$ & $0.68(0.20)$ & 5 \\
\hline \multicolumn{5}{|c|}{25 Jun, patch 2} \\
\hline $0 \mathrm{~m}$ & $1.2(0.6)$ & 7.4 (1.4) & $0.14 \quad(0.07)$ & 5 \\
\hline $3 \mathrm{~m}$ & $1.8(0.6)$ & $7.2(1.3)$ & $0.24 \quad(0.09)$ & 5 \\
\hline $6 \mathrm{~m}$ & $1.2(0.4)$ & $3.0(0.9)$ & $0.44 \quad(0.21)$ & 4 \\
\hline \multicolumn{5}{|c|}{$7 \mathrm{Jul}$, patch 1} \\
\hline $0 \mathrm{~m}$ & $28.4(7.7)$ & $33.8(10.7)$ & $1.15(0.46)$ & 5 \\
\hline $3 \mathrm{~m}$ & $58.2(7.8)$ & $37.8(6.1)$ & $1.68(0.30)$ & 5 \\
\hline $6 \mathrm{~m}$ & $33.0 \quad(14.9)$ & $7.8(3.4)$ & 5.24 (1.89) & 4 \\
\hline \multicolumn{5}{|c|}{7 Jul, patch 2} \\
\hline $0 \mathrm{~m}$ & $6.0(1.2)$ & $7.2(1.9)$ & $1.02(0.29)$ & 5 \\
\hline $3 \mathrm{~m}$ & 7.8 (1.9) & $7.6(1.7)$ & $1.28(0.35)$ & 5 \\
\hline $6 \mathrm{~m}$ & $22.8(6.4)$ & $14.6(1.9)$ & $1.96(0.80)$ & 5 \\
\hline
\end{tabular}

iments in 2002 indicated that deposition on a standard substratum was affected by distance from the natural deposition sites on a scale of meters within pools.

\section{DISCUSSION}

\section{Scarcity of deposition sites for Haminaea vesicula}

Estimates of percent cover of firm substrata, combined with the choice experiment, demonstrated that the preferred substrata for Haminaea vesicula egg deposition were indeed scarce within False Bay. The deposition of large numbers of egg ribbons on experimentally added substrata indicated that adults of $H$. vesicula in this habitat travel substantial distances before encountering suitable deposition sites and use sites intensively when they reach them. Greater deposition per adult occurred at substrata added at greater distances from natural deposition sites, which indicates that scarcity of natural sites is experienced on the spatial scales of habitat within False Bay.

Scarcity of deposition sites for Haminaea vesicula in False Bay contrasts with $H$. vesicula at some other habitable sites. Argyle Lagoon, only $20 \mathrm{~km}$ away, offers abundant sites for egg deposition on a filamentous green alga in areas inhabited by adult $H$. vesicula (I. Falkner, C. Henzler, T. MacDonald, D. Vaughn unpubl.), and $H$. vesicula occurs at some sites where eelgrass is abundant. False Bay does not represent a 
limitation that $H$. vesicula encounters everywhere, but it does illustrate a limitation that occurs in extensive areas otherwise suitable for recruitment, survival, growth, and egg production.

The experiments imply that adult snails must travel to encounter sites for egg deposition. Costs of travel to scarce deposition sites may impose increased risk of predation, increased energy loss (as in the copious mucus secreted by crawling adults of Haminaea vesicula), decreased foraging, deferred reproduction, or eventual acceptance of suboptimal deposition sites.

\section{Scarcity of deposition sites: a hidden cost of benthic development}

This study was prompted by published estimates of mortality rates and costs of protection. Development in benthic egg masses appears to offer greater safety than pelagic development, but there are costs (Pechenik 1979). An obvious cost is the protective materials that surround embryos but are not incorporated into the developing offspring. The protective capsules or gel coats for benthic embryos can double parental investment per embryo (Stickle 1973, Perron 1981, Lee \& Strathmann 1998), but mortality rates may be greatly reduced by the protection (Strathmann 1985, Rumrill 1990), which could compensate for costs of protective coats within a few days. One can calculate the time when there would be equal numbers of surviving offspring from pelagic and benthic development if fecundity is decreased to the extent that organic materials are allocated to protective coats. Estimates from the literature indicate mortality rates exceeding $0.1 \mathrm{~d}^{-1}$ and often about $0.2 \mathrm{~d}^{-1}$ for small planktonic larvae (Strathmann 1985, Rumrill 1990, Morgan 1995, Lamare \& Barker 1999). Mortality rates for pelagic embryos can be greater yet (Ohman \& Hirche 2001, López-Urrutia et al. 2004). Most estimates are less than $0.01 \mathrm{~d}^{-1}$ for protected benthic embryos. Protective coats comprise 20 to $50 \%$ of the organic material in benthic spawn of a variety of gastropod molluscs (Stickle 1973, Perron 1981, Lee \& Strathmann 1998). A constant mortality rate of $m=-\ln \left(N_{t} / N_{0}\right) / t$ is assumed. The time at which there will be equal numbers of offspring is then:

$$
t=\ln (F) /\left(m_{\mathrm{b}}-m_{\mathrm{p}}\right)
$$

where $F$ is the ratio of numbers of benthic eggs to pelagic eggs, $m_{\mathrm{p}}$ is the pelagic mortality rate, and $m_{\mathrm{b}}$ is the benthic mortality rate.

For Haminaea vesicula, about $30 \%$ of the dry organic weight of the spawn is the gelatinous coat (Lee \& Strathmann 1998). If one assumes that the costs of protective coats reduce fecundity to 0.7 of that of a pelagic spawn and that the benthic mortality rate is $0.01 \mathrm{~d}^{-1}$, then this calculation estimates the time for compensating for costs of protective coats to be only $2 \mathrm{~d}$ if pelagic mortality were $0.2 \mathrm{~d}^{-1}$ and $4 \mathrm{~d}$ if pelagic mortality were $0.1 \mathrm{~d}^{-1}$. The calculation overestimates costs of protective coats because pelagic eggs have some organic material in their coats. For echinoids, estimates of percent of spawn that is coating gel range from 3 to $17 \%$ of the organic or energy content (Bolton et al. 2000, Marsh \& Manahan 2000, Podolsky 2002). Complications are numerous. Production of protective coats requires complex reproductive organs. Greater reproductive investment can reduce adults' capacity for escape responses, a cost that can vary with type of escape and sex and that can occur with both benthic deposition and free spawning (Brokordt et al. 2000, 2003). Nevertheless, calculations based solely on organic material in spawn and mortality rates of offspring demonstrate that costs of protection can be rapidly repaid by reduced mortality and thus raise the question, why is benthic development not more common for embryos of benthic species? Part of the answer may be a hidden cost of reduced reproductive output if benthic sites for egg deposition are scarce (Pechenik 1978, 1999, Brenchley 1981, DeMartini 1991, Hastings 1992).

\section{Are sites for egg deposition commonly scarce?}

We have demonstrated that sites for benthic egg deposition are scarce for Haminaea vesicula in some occupied habitats. Other examples of substrate limitation for egg deposition have been reported (Pechenik 1978, Brenchley 1981, D'Asaro 1986, DeMartini 1991, Hastings 1992, Warner et al. 1995, Kuhlmann 1997, Borg et al. 2002), but how common is this situation? Swanson (2004) measured crawling distances of a snail that were large relative to spacing of potential deposition sites. We expect constraints from scarce deposition sites to occur frequently but not universally with benthic development. Other animals depositing benthic egg masses in False Bay illustrate this variation. Another cephalaspidean gastropod, Melanochlamys diomedea, tethers its gelatinous egg mass in the sand and does not depend on firm substrata for deposition of its eggs. This advantage has associated costs. The tethered mass is globose rather than ribbon shaped and has more gel per embryo than does the egg ribbon of H. vesicula (Lee \& Strathmann 1998). Oxygen limitation is more likely to affect rate of development and hatching size of central embryos in the thicker mass of M. diomedea (Strathmann \& Strathmann 1995, Cohen \& Strathmann 1996). Weighting with sand grains, as in naticid egg collars, may also involve trade-offs, since 
sand grains restrict oxygen diffusion. Egg masses that drift along the bottom (e.g. those of the annelid Nereis vexillosa) sacrifice the advantages of deposition in especially safe sites. Brooding is an option for protection of benthic embryos, but in many groups of marine animals, restrictions associated with adult size preclude brooding in species with large adults (Strathmann \& Strathmann 1982). Large crustaceans brood, but at least some incur substantial costs in time and energy in ventilating brooded embryos (Fernández et al. 2000, Baeza \& Fernández 2002). These limitations on benthic development occur on sand or mud, which is the benthic habitat for most of the earth's surface. Even on rock, where firm substrata abound, sites safe for benthic development may be scarce, or they may be distant from sites most favorable for juveniles and adults (Spight 1977). Habitats that regularly support adult populations can differ greatly in suitability for egg deposition, but this limitation is seldom apparent without experimental intervention.

Acknowledgements. This study was supported by a Blinks fellowship to Y.J.v.D., NSF grant IBN0113603 to R.R.S., and the Friday Harbor Laboratories of the University of Washington. We are grateful to the staff of the Friday Harbor Laboratories, to M. von Dassow, L. A. McEdward and S. G. Brady for their help with field observations, to R. E. Emlet, P. W. Gabrielson, D. K. Padilla, and R. D. Podolsky, M. F. Strathmann, and an anonymous reviewer for advice, and to C. S. Cohen, C. A. Kelly, S. G. Morgan, and J. A. Schmidt, whose observations on egg deposition encouraged this study.

\section{LITERATURE CITED}

Baeza JA, Fernández M (2002) Active brood care in Cancer setosus (Crustacea: Decapoda): the relationship between female behavior, embryo oxygen consumption and cost of brooding. Funct Ecol 16:241-251

Biermann CH, Schinner GO, Strathmann RR (1992) Influence of solar radiation, microalgal fouling, and current on deposition site and survival of embryos of a dorid nudibranch gastropod. Mar Ecol Prog Ser 86:205-215

Bolton TF, Thomas FIM, Leonard CN (2000) Maternal energy investment in eggs and jelly coats surrounding eggs of the echinoid Arbacia punctulata. Biol Bull (Woods Hole) 199: $1-5$

Borg ÅA, Forsgren E, Magnhagen C (2002) Plastic sex-roles in the common goby - the effect of nest availability. Oikos 98:105-115

Brenchley GA (1981) Limiting resources and the limits to reproduction in the 'mud' snail Ilyanassa obsoleta in Barnstable Harbor, Massachusetts. Biol Bull (Woods Hole) 161:323

Brokordt KB, Himmelman JH, Nusetti OA, Guderley HE (2000) Reproductive investment reduces recuperation from exhaustive escape activity in the tropical scallop Euvola zizac. Mar Biol 137:857-865

Brokordt KB, Guderley HE, Guay M, Gaymer CF, Himmelman JH (2003) Sex differences in reproductive investment: maternal care reduces escape response capacity in the whelk Buccinum undatum. J Exp Mar Biol Ecol 291: $161-180$
Cohen CS, Strathmann RR (1996) Embryos at the edge of tolerance: effects of environment and structure of egg masses on supply of oxygen to embryos. Biol Bull (Woods Hole) 190:8-15

D'Asaro CN (1986) Egg capsules of eleven marine prosobranchs from northwest Florida. Bull Mar Sci 39:76-91

De Martini EE (1991) Spawning success of the male plainfin midshipman. II. Substratum as a limiting spatial resource. J Exp Mar Biol Ecol 146:235-251

Dethier, MN, Graham ES, Cohen S, Tear LM (1993) Visual versus random-point percent cover estimations: 'objective' is not always better. Mar Ecol Prog Ser 96:93-100

Fernández M, Bock C, Pörtner H-O (2000) The cost of being a caring mother: the ignored factor in the reproduction of marine invertebrates. Ecol Lett 3:487-494

Gibson GD, Chia FS (1989) Embryology and larval development of Haminoea vesicula Gould (Opisthobranchia: Cephalaspidea). Veliger 32:409-412

Gibson GD, Chia FS (1991) Contrasting reproductive modes in 2 sympatric species of Haminaea (Opisthobranchia: Cephalaspidea). J Molluscan Stud 57:49-60

Hastings PA (1992) Nest-site size as a short-term constraint on the reproductive success of paternal fishes. Environ Biol Fish 34:213-218

Keough MJ (1986) The distribution of a bryozoan on seagrass blades: settlement, growth, and mortality. Ecology 67 : 846-857

Kuhlmann ML (1997) Regulation of fish reproduction by a predatory gastropod: an experimental investigation of indirect effects in a seagrass community. J Exp Mar Biol Ecol 218:199-214

Lamare MD, Barker MF (1999) In situ estimates of larval development and mortality in the New Zealand sea urchin Evechinus chloroticus (Echinodermata: Echinoidea). Mar Ecol Prog Ser 180:197-211

Lee CE, Strathmann RR (1998) Scaling of gelatinous clutches: effects of siblings' competition for oxygen on clutch size and parental investment per offspring. Am Nat 151: 293-310

López-Urrutia Á, Harris RP, Smith T (2004) Predation by calanoid copepods on the appendicularian Oikopleura dioica. Limnol Oceanogr 49:303-307

Marliave JB (1981) High intertidal spawning under rockweed, Fucus distichus, by the sharpnose sculpin, Clinocottus acuticeps. Can J Zool 59:1122-1125

Marsh AG, Manahan DT (2000) Metabolic differences between 'demersal' and 'pelagic' development of the Antarctic sea urchin Sterechinus neumayeri. Mar Biol 137: 215-221

McEdward LR 1992) Morphology and development of a unique type of pelagic larva in the starfish Pteraster tesselatus (Echinodermata: Ateroidea). Biol Bull (Woods Hole) 182:177-187

Morgan SG (1995) Life and death in the plankton: larval mortality and adaptation. In: McEdward L (ed) Ecology of marine invertebrate larvae. CRC Press, Boca Raton, FL, p 279-321

Ohman MD, Hirche HJ (2001) Density-dependent mortality in an oceanic copepod population. Nature 412:638-641

Pechenik JA (1978) Adaptations to intertidal development: studies of Nassarius obsoletus. Biol Bull (Woods Hole) 154: 282-291

Pechenik JA (1979) Role of encapsulation in invertebrate life histories. Amer Nat 114:859-870

Pechenik JA (1999) On the advantages and disadvantages of larval stages in benthic marine invertebrate life cycles. Mar Ecol Prog Ser 177:269-297 
Perron FE (1981) The partitioning of reproductive energy between ova and protective capsules in marine gastropods of the genus Conus. Am Nat 118:110-118

Podolsky RD (2002) Fertilization ecology of egg coats: physical versus chemical contributions to fertilization success of free-spawned eggs. J Exp Biol 205:1657-1668

Podolsky RD (2003) Integrating development and environment to model reproductive performance in natural populations of an intertidal gastropod. Integr Comp Biol 43:450-458

Rohlf FJ, Sokal RR (1969) Statistical tables. WH Freeman, San Francisco, CA

Rouse G, Fitzhugh K (1994) Broadcast fables: is external fertilization really primitive? Sex, size, and larvae in sabellid polychaetes. Zool Scr 23:271-312

Ruckelshaus MH (1998) Spatial scale of genetic structure and an indirect estimate of gene flow in eelgrass, Zostera marina. Evolution 52:330-343

Rumrill SS (1990) Natural mortality of marine invertebrate larvae. Ophelia 32:163-198

Shimek RL (1981) Neptunea pribiloffensis (Dall 1919) and Tealia crassicornis (Müller 1776): on a snail's use of babysitters. Veliger 24:62-66

Spight TM (1977) Do intertidal snails spawn in the right places. Evolution 31:682-691

Editorial responsibility: Charles Peterson (Contributing Editor), Morehead City, North Carolina, USA
Stickle WB (1973) The reproductive physiology of the intertidal prosobranch Thais lamellosa (Gmellin). I. Seasonal changes in the rate of oxygen consumption and body component indexes. Biol Bull (Woods Hole) 144:511-524

Strathmann RR (1974) Introduction to function and adaptation in echinoderm larvae. Thalassia Jugosl 10:321-339

Strathmann RR (1985) Feeding and nonfeeding larval development and life-history evolution in marine invertebrates. Annu Rev Ecol Syst 16:339-361

Strathmann RR, Strathmann MF (1982) The relationship between adult size and brooding in marine invertebrates. Am Nat 119:91-101

Strathmann RR, Strathmann MF (1995) Oxygen supply and limits on aggregations of embryos. J Mar Biol Assoc UK 75:413-428

Swanson CA (2004) Effect of substrate availability and conspecific cues on communal oviposition in the apple murex snail Phyllonotus pomum. Mar Ecol Prog Ser 275: 175-184

Warner RR, Lejeune FWP, van den Berghe E (1995) Dynamics of female choice for parental care in a fish species where care is facultative. Behav Ecol 6:73-81

Zar JH (1984) Biostatistical analysis. Prentice Hall, Englewood Cliffs, NJ

Submitted: March 16, 2004; Accepted: February 6, 2005

Proofs received from author(s): May 23, 2005 